\title{
Correction to: Epigenetic Regulation of SNAP25 Prevents Progressive Glutamate Excitotoxicty in Hypoxic CA3 Neurons
}

\author{
Suryanarayan Biswal ${ }^{1} \cdot$ Debashree Das ${ }^{1} \cdot$ Kalpana Barhwal $^{2} \cdot$ Ashish Kumar $^{1} \cdot$ Tapas Chandra Nag $^{3}$. \\ Mahendra Kumar Thakur ${ }^{4}$. Sunil Kumar Hota ${ }^{1}$. Bhuvnesh Kumar ${ }^{1}$
}

Published online: 16 December 2019

(C) Springer Science+Business Media, LLC, part of Springer Nature 2019

\section{Correction to: Mol Neurobiol (2017) 54:6133-6147 \\ https://doi.org/10.1007/s12035-016-0156-0}

The original version of this article unfortunately contained mistake.

The authors noticed that some anomalies in "Figure 5" of the manuscript.

The figure for different timelines of hypoxic exposure was erroneously picked from the same folder which could be because of human error or uploading of wrong file during the compilation of results.

The authors sincerely apologize for the inadvertent mistake and hereby publish the correct Figure 5.

The online version of the original article can be found at https://doi.org/ 10.1007/s12035-016-0156-0

Sunil Kumar Hota

drsunilhota@hotmail.com

1 Experimental Biology Division, Defence Institute of High Altitude Research, Defence Research and Development Organisation, c/o 56 APO, Leh-Ladakh, Jammu \& Kashmir Pin-901205, India

2 Department of Physiology, All India Institute of Medical Sciences, Bhubaneswar, India

3 Department of Anatomy, All India Institute of Medical Science, New Delhi, India

4 Department of Zoology, Banaras Hindu University, Varanasi, India 


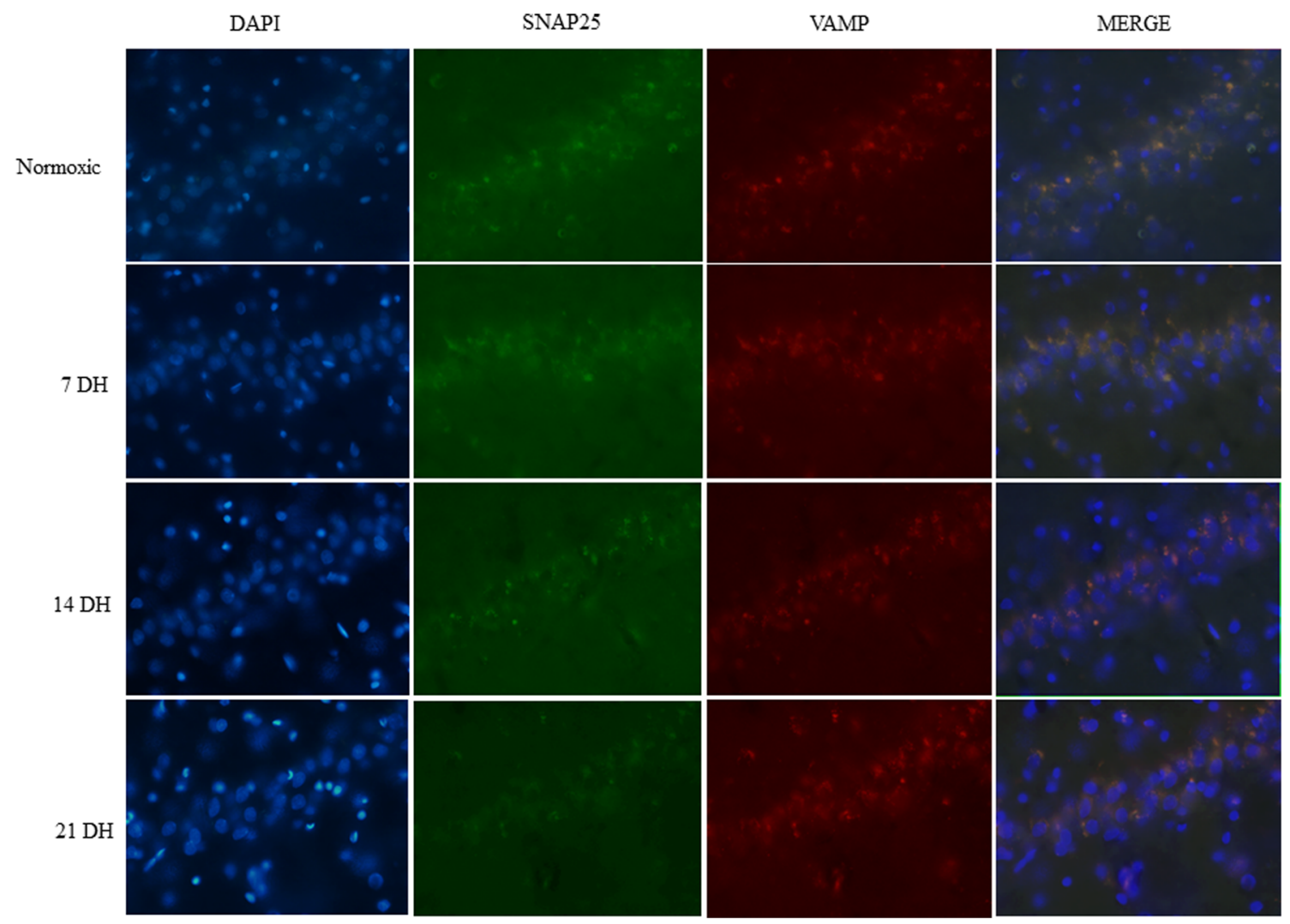

